2002s-40

Selective Penalization Of

Polluters: An Inf-Convolution Approach

\author{
Ngo Van Long, Antoine Soubeyran
}

Série Scientifique

Scientific Series

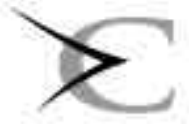

CI I RANO

en unalyae des organisalions

Montréal

Avril 2002 


\section{CIRANO}

Le CIRANO est un organisme sans but lucratif constitué en vertu de la Loi des compagnies du Québec. Le financement de son infrastructure et de ses activités de recherche provient des cotisations de ses organisationsmembres, d'une subvention d'infrastructure du ministère de la Recherche, de la Science et de la Technologie, de même que des subventions et mandats obtenus par ses équipes de recherche.

CIRANO is a private non-profit organization incorporated under the Québec Companies Act. Its infrastructure and research activities are funded through fees paid by member organizations, an infrastructure grant from the Ministère de la Recherche, de la Science et de la Technologie, and grants and research mandates obtained by its research teams.

\section{Les organisations-partenaires / The Partner Organizations}

-École des Hautes Études Commerciales

-École Polytechnique de Montréal

-Université Concordia

-Université de Montréal

-Université du Québec à Montréal

-Université Laval

-Université McGill

-Ministère des Finances du Québec

-MRST

-Alcan inc.

- AXA Canada

-Banque du Canada

-Banque Laurentienne du Canada

-Banque Nationale du Canada

- Banque Royale du Canada

- Bell Canada

- Bombardier

-Bourse de Montréal

-Développement des ressources humaines Canada (DRHC)

-Fédération des caisses Desjardins du Québec

-Hydro-Québec

-Industrie Canada

-Pratt \& Whitney Canada Inc.

-Raymond Chabot Grant Thornton

-Ville de Montréal

(C) 2002 Ngo Van Long et Antoine Soubeyran. Tous droits réservés. All rights reserved. Reproduction partielle permise avec citation du document source, incluant la notice (C).

Short sections may be quoted without explicit permission, if full credit, including @ notice, is given to the source.

Les cahiers de la série scientifique $(\mathrm{CS})$ visent à rendre accessibles des résultats de recherche effectuée au CIRANO afin de susciter échanges et commentaires. Ces cahiers sont écrits dans le style des publications scientifiques. Les idées et les opinions émises sont sous l'unique responsabilité des auteurs et ne représentent pas nécessairement les positions du CIRANO ou de ses partenaires.

This paper presents research carried out at CIRANO and aims at encouraging discussion and comment.

The observations and viewpoints expressed are the sole responsibility of the authors. They do not necessarily represent positions of CIRANO or its partners.

\section{ISSN 1198-8177}




\title{
Selective Penalization Of Polluters: An Inf-Convolution Approach*
}

\author{
Ngo Van Long ${ }^{\dagger}$ and Antoine Soubeyran ${ }^{*}$
}

\begin{abstract}
Résumé / Abstract
On modélise un oligopole hétérogène : les firmes ont des coûts différents et des paramètres de pollution différents. On montre que les taux de taxes optimales imposées sur les émissions ne sont pas les mêmes. On appelle cette propriété la pénalisation sélective. Il existe donc un conflit entre l'équité et l'efficacité. Le résultat principal de notre article est Le Théorème de la Distorsion Optimale. La structure des taxes optimales exige que les firmes aux coûts les plus élevés paient les taxes les plus élevées. Un autre résultat s'appelle le Théorème sur le motif pro-concentration.

In this paper, we consider an asymmetric polluting oligopoly: firms have different production costs, and their pollution characteristics may also be different. We will demonstrate that, in this case, optimal tax rates per unit of emission are not the same for all firms. We call this property "selective penalization", or "favoritism in penalties." Thus, the "efficiency" objective may be served only at the expense of "fairness'. One of our main results is the Optimal Distortion Theorem.. We show that even in the case $w$ here the rates of emission per unit of output are identical for all firms, the efficient tax structure requires that high cost firms pay a higher tax rate on emissions. Our result implies that the efficient tax structure favors the efficient firms, but the magnitude of the favors is a decreasing function of the marginal cost of public fund. Another characterization of optimal tax structure is our Pro-concentration Motive Theorem. Optimal taxes penalize the inefficient firms more, and thus increases the concentration of the industry, as measured by the Herfindahl index. In fact, we show that the variance of the distribution of the firms' tax-inclusive marginal costs after the imposition of efficient taxes exceeds the variance that would be obtained if there were no taxes. We call this the Magnification Effect: the variance of marginal costs is magnified by a factor which depends on the marginal cost of public fund.
\end{abstract}

Key words: Pollution, environmental regulation, oligopoly

Mots-clés : Pollution, réglementations environnementales, oligopole

JEL classifications: Q20, D60, D63

\footnotetext{
${ }^{*}$ We wish to thank Peter Neary and Raymond Riezman for very helpful comments.

† Ngo Van Long: Department of Economics, McGill University, and Cirano. Email: longn@ cirano.qc.ca

*Antoine Soubeyran: GREQAM, Université de la Méditerranée. Email:soubey@ univ-aix.fr
} 


\section{Introduction}

When production generates pollution as a by-product, competitive ..rms over-produce in the sense that marginal social cost exceeds price. Under perfect competition, a Pigouvian tax equal to marginal damage cost is called for. This rule applies whether ..rms are identical or not. Thus, under perfect competition, all polluting ..rms are treated fairly by a regulator that seeks to achieve ed ciency: the tax rate per unit of emission is the same for all ..rms, even under heterogeneity of production costs. When the market is not competitive ${ }^{1}$, however, as we will show below, it is no longer true that ed ciency can be achieved by a uniform tax rule.

In this paper, we consider an asymmetric polluting oligopoly: ..rms have dixerent production costs, and their pollution characteristics may also be dixerent. We will demonstrate that, in this case, optimal tax rates per unit of emission are not the same for all ..rms. We call this property "selective penalization", or "favoritism in penalties." Thus, the "ec ciency" objective may be served only at the expense of "fairness." We do not propose to resolve the issue of fairness, or equity, here. Our objective is to analyze the direction of "favoritism in penalties": how the et ciency-inducing ..rm-speci..c tax structure depends on the structure of (heterogenous) production costs, and heterogenous pollution-output ratio. We wish to determine which types of ..rms (low cost, or high cost ..rms) should be penalized more.

A symmetry is important, because it is a prevalent real world feature, and because it introduces another source of distortion: in a Cournot equilibrium, marginal production costs are not equalized across ..rms, resulting in production ineф ciency at any given total output.

\footnotetext{
${ }^{1}$ B uchanan (1969) and B arnett (1980) have shown that the optimal tax per unit of emission under monopoly is less than the marginal damage cost (and it can be negative). K atsoulacos and X epapadeas (1995), consider the case of a symmetric polluting oligopoly (i.e., they assume that ..rms are identical) and show that if the number of ..rms is endogenous and if there are ..xed costs, the optimal Pigouvian tax could exceed the marginal damage cost, because free entry may result in an excessive number of ..rms.
} 
In this context, pollution taxes or pollution standards must seek to remedy both the environmental problem and the intra-industry production ine ciency problem. With asymmetric oligopoly, the regulator would want to be able to correct distortion on a ..rm-speci..c basis. While de jure dixerential treatments to ..rms in the same industry (in the sense that dixerent standards apply to dixerent ..rms), may be politically unacceptable in most economies, de facto dixerential treatments (e.g., dixerent degrees of enforcement and veri..cation) may be feasible. In what follows, whenever the terms "..rm-speci..c tax rates", or "..rm-speci..c pollution standards" are used, they should be interpreted in the de facto sense.

The objective of this paper two-fold. Our ..rst aim is to characterize the structure of optimal ..rm-speci..c emission tax rates, and to provide an intuitive explanation of our results on dixerential treatments. Here, we go a step further than just establishing the conditions for unequal treatment of equals, which have been provided elsewhere (Salant and Schaxer, 1996, 1999, Long and Soubeyran, 1997a,b, 2001). We fully characterize the direction of bias. Our second aim is to highlight the confict between el ciency and equity. We show that, in the case of taxation, ..rms that are equally polluting (i.e., their emissions per unit of output are identical) may be taxed dixerently, when their production costs are dixerent. In a sense, this is inequitable. In the case where regulation is by means of pollution standards, we again show a conłict between eф ciency and equity: eф ciency may require that dixerent standards be imposed on ex-ante identical ..rms.

One of our main results is the Optimal Distortion Theorem. We show that even in the case where the rates of emission per unit of output are identical for all ..rms, the el cient tax structure requires that high cost ..rms pay a higher tax rate on emissions. Our result implies that the ed cient tax structure favors the el cient ..rms, but the magnitude of the favors is a decreasing function of the marginal cost of public fund. More generally, we de..ne the Pigouvian distortion for ..rm $\mathrm{i}$ as the dixerence between the tax rate on its output and 
the adjusted ${ }^{2}$ marginal pollution damage caused by an extra unit of its output, and show that the optimal Pigouvian distortion for ..rm $\mathrm{i}$ is greater than that for ..rm $\mathrm{j}$, if and only if the marginal social cost of ..rm $i$ is greater than that of ..rm j. (Marginal social cost is the sum of marginal production cost and adjusted marginal damage cost.) Another characterization of optimal tax structure is our Proconcentration M otive Theorem. Optimal taxes penalize the inec cient ..rms more, and thus increases the concentration of the industry, as measured by the Her..ndahl index. In fact, we show that the variance of the distribution of the ..rms'tax-inclusive marginal costs after the imposition of el cient taxes exceeds the variance that would be obtained if there were no taxes. We call this the Magni..cation Effect: the variance of marginal costs is magni..ed by a factor which depends on the marginal cost of public fund. From a mathematical point of view, our result has a nice geometric interpretation: We show that optimal taxes can be obtained as a solution of minimizing the distance between a hyperplane and a reference point. Our approach is an application of the duality theory using conjugate function and inf-convolution.

Our main focus in on ..rm-speci..c taxation on emissions. A brief section on ..rm-speci..c standards is included to show the general applicability of our method ${ }^{3}$.O ur derivation of optimal taxes and optimal standards (in slightly dixerent models) shows that there is a uni..ed framework for analyzing ..rm-speci..c penalties.

In the models we present below, we use a two-stage game framework. In the ..rst stage, the regulator sets ..rm-speci..c emission taxes or standards. In the second stage, ..rms compete in the ..nal good market. To ..x ideas, we focus on the case where ..rms produce a

\footnotetext{
${ }^{2} \mathrm{~A} n$ adjustment factor is applied to account for the marginal cost of public fund.

${ }^{3}$ We do not seek to compare taxes to standards, because there exists al ready a large literature on that subject. In fact, the model we develop to analyze optimal standards is quite dixerent from the model we use to analyze optimal taxes, and therefore it would not make sense to discuss, using our results, the relative attractiveness of these two policy measures.
} 
homogenous good, and compete à la Cournot. However, our analysis can easily be adapted to deal with other cases, such as B ertrand competition with dixerentiated products, spatial competition (as in the Hotelling model), and even markets in which some ..rms are Stackelberg leaders.

The games considered in this paper belong to the class of games called "cost manipulation games with costs of manipulating" (see Long and Soubeyran, 2001a). The regulator uses the chosen policy instrument to axect, on a discriminatory basis, the marginal costs of individual ..rms. This in turn axects their equilibrium outputs and market shares. The costs of manipulating can take dixerent forms. In the case of taxation, when the marginal cost of public funds exceeds unity ${ }^{4}$, these costs include the loss of tax revenue when the regulator changes the tax structure In the case of standards, ..rms are induced to acquire costly equipment to reduce the pollution generated by their production process. Such equipment alters the marginal production costs.

We are able to provide a uni..ed treatment of ..rm-speci..c pollution policies because we transform variables in such a way that all modes of intervention (in distinct models of emission generation) can be seen to have the same basic structure. We show that maximizing the ..rst stage objective with respect to one of the environmental instruments (such as Pigouvian taxes, speci..c pollution standards, tradable pollution permits) is equivalent to choosing the Cournot equilibrium quantities. This is because the discriminatory use of policy instruments in the ..rst stage amounts to the same thing as manipulating the marginal costs of production which in turn axect second-stage equilibrium outputs.

\section{Selective Penalization by Pigouvian Taxes}

In this section present our basic model of an asymmetric polluting oligopoly, and derive the optimal ..rm-speci..c Pigouvian taxes.

\footnotetext{
${ }^{4}$ See Ballard et al. (1985) for estimates of the marginal cost of public ..nance.
} 
Here, our major task is to show how the optimal ..rm-spec..c taxes are related to the structure of heterogenous costs and heterogenous emission-output ratios. Our main results are summarized in Proposition ODT (Optimal Distortion Theorem). A ccording to this theorem, in a oligopoly consisting of ..rms with non-identical costs, the optimal Pigouvian tax for each ..rm must deviate from its adjusted marginal damage per unit of output, and such deviations vary among ...rms: the deviation should be the greatest for the most inec cient ..rm, and lowest for the most ed cient ..rms. In general, inet cient ..rms are penalized more, relative to ec cient ..rms.

\subsection{The basic model}

We consider a polluting oligopoly consisting of $n$ non-identical ..rms producing a homogenous ...nal gopd. Let $I=f 1 ; 2 ; \ldots ;$ ng: The total output of the ..nal good is $Q=i 21 \mathrm{q}$. The inverse demand function for the ..nal good is $P=P(Q)$ where $P(Q)<0$. In this model, emission is proportional to output: $\mathrm{e}(\mathrm{q})={ }{ }_{\mathrm{i}} \mathrm{q}$. In general, ${ }_{i} \in{ }_{j}$. This is the ..rst source of heterogeneity. Firm $i$ has production cost $c_{i}(q)$. The subscript $i$ in $c_{i}(:)$ indicates that in general ..rms are heterogenous also in production cost. Firms sell their good in the same market place, but they are located at dixerent points. We represent this third source of heterogeneity (distance from the central market place) by assuming that ..rm i must incur a transport cost $d_{i}$ per unit of output (in general $d_{i} \in d_{j}$ ). We assume that ..rm i must pay a tax $t_{i}$ per unit of its emission. (The regulator must set the tax rates optimally.) $\mathrm{T} h$ pro..t function is

$$
1 / 4=P(Q) q \text { i } c_{i}(q) i \quad t_{i}{ }^{2} q \text { i } d_{i} q
$$

We de.ne

$$
i_{i}{ }^{\prime} t_{i}{ }^{\prime} i
$$

so that $i_{i}$ is the tax per unit of output of ..rm i. It is convenient to de. ne $!_{i}{ }^{\prime} d_{i}+i_{i}$. The pro..t function becomes

$$
1 / \mathbb{A}=P(Q) q_{i} C_{i}\left(q_{i} !_{i}\right)
$$


where $C_{i}\left(q_{;} !_{i}\right)$ is the (tax-inclusive) total cost function:

$$
c_{i}\left(q_{;} !_{i}\right)^{\prime} !_{i} q+c_{i}(q)
$$

The (tax-inclusive) average variable cost function is:

$$
1 / p\left(q ; !_{i}\right)=!_{i}+\frac{c_{i}(q)}{q}
$$

and the (tax-inclusive) marginal cost function is

$$
\mu_{i}\left(q ; !_{i}\right)=!_{i}+q_{i}(q)
$$

The dixerence between $\mu_{i}$ and $1 / 2$, de. ned as $r_{i}$, measures the degree of convexity of the cost function. We have

$$
r_{i}=\mu_{i} i \quad 1 / i=c_{i}^{9}(q) \text { i } \frac{c_{i}(q)}{q}
$$

If $c_{i}(:)$ is linear, then $r_{i}$ equals zero identically. If $c_{i}(:)$ is strictly convex, then $r_{i}$ is positive for all $z_{i}>0$.

We will show how the government can optimally manipulate the tax-inclusive costs of the ..rms so as to maximize social welfare. To do this, we set up the problem as a two-stage game. In the ..rst stage, the government sets ..rm-speci..c taxes, and in the second stage, ..rms compete as Cournot rivals, taking tax rates as given. As usual, to solve for the optimal taxes, we must ..rst analyse the equilibrium of the game in stage two.

2.2. Stage two: Cournot equilibrium given tax rates

The ..rst order condition for an interior equilibrium for ..rm $\mathrm{i}$ is

$$
\frac{@ / 4}{@ q}=P(Q) q+P(Q) \text { i } \mu=0 ; \quad \text { i } 2 \text { I }
$$

We assume that these conditions determine a unique ${ }^{5}$ Cournot equilibrium ( $($; $; \mathbf{q}, \mathrm{i} 2 \mathrm{I})$; where the hat over a symbol indicates that it is the

\footnotetext{
${ }^{5}$ For assumptions ensuring existence and uniqueness of equilibrium, see Long and Soubeyran (2000).
} 
Cournot equilibrium value. It is convenient to express the equilibrium output of ..rm i as a function of the equilibrium output of the industry, and of the parameters of ..rm i's (tax-inclusive) cost function:

$$
\mathbf{q}=\mathbf{q}\left(\mathbf{Q}_{;} !_{\mathrm{i}}\right)
$$

Inserting (3) and (5) into (4), we obtain

$$
P q(\mathbb{Q}) \mathbf{q}\left(\mathbb{Q}_{;} !_{\mathrm{i}}\right)+\mathrm{P}\left(\mathbb{Q}_{)}\right)=!_{\mathrm{i}}+\mathrm{c}_{\mathrm{i}}^{0} \mathbf{q}\left(\mathbb{Q}_{;} !_{\mathrm{i}}\right)
$$

Summing (6) over all $i$, we obtain the identity

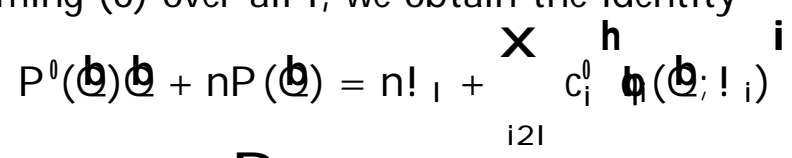

where ! , $(1=n){ }_{i 21}^{\mathrm{P}} !_{\mathrm{i}}$. Equation (7) indicates that the equilibrium output can be determined from the knowledge of the $!_{i}$ 's. Given the $!_{i}$ 's, we assume that there exists a unique $\mathbb{Q}$ that satis..es (7). (See Long and Soubeyran (2000) for sul cient conditions for uniqueness). Thus we write

$$
\text { Q }=Q(!)
$$

where! $\left(!_{1} ; !_{2} ; \ldots ; ; ! n\right)$ :

We now express, the equilibrium, pro..t of ...rm i as follows

$$
\begin{aligned}
& b_{4}=\phi_{i} b_{2} \mathbf{q}=\phi_{i} p_{i}+p_{i} b_{2} \mathbf{q} \\
& =\left[i p q \mathbf{q}^{2}+\mathbf{b}(\mathbf{q}) \mathbf{q}\right. \\
& =\left[i \rho g \mathbf{q}^{2}+\mathbf{q} c_{i}^{0}(\mathbf{q}) ; c_{i}(\mathbf{q})\right.
\end{aligned}
$$

where we have made use of the Cournot equilibrium condition

$$
\phi_{i} p_{i}=[i \rho q \mathbf{q}
$$

Expression (9) deserves some comments. Since the pro..t expression in (9) incorporates the Cournot equilibrium condition (10), it indicates that, in the ..rst stage of the game, while the government can 
manipulate the $\mathbf{q}$ and $\phi$ via the choice of the policy parameters $i_{i}$, it cannot violate the Cournot equilibrium condition. (Technically, this is very much like the incentive compatibility constraint in principalagent problems: the principal cannot ignore economic agents' equilibrium conditions.) We now turn to a complete analysis of the ..rst stage of the game.

\subsection{The ..rst stage: optimization by the government}

The objective of the government is to maximize a weighted sum of pro..ts, consumers' surplus, and tax revenue, minus the damage cost caused by pollution. The weight given to consumers' surplus is ${ }^{-}>0$. The weight ${ }^{\circ}, 1$ is a measure of the marginal cost of public fund. We will restrict attention to the empirically relevant range of ${ }^{\circ}: 1 \cdot{ }^{\circ} \cdot 2$ (see Ballard et al. (1985) for discussion, and for estimates of ${ }^{\circ}$ for the US economy). Thus, welfare is

$$
W={ }_{i 21}^{X} 1 / 4+{ }^{-} S+{ }^{0} t_{i 21} t_{i} \text { i } D(E) \text {, where } 1 \cdot \circ \cdot 2 \text {, }
$$

where $E={ }_{i 21}^{P}, E, D(E)$ is the damage cost, and $S$ is the consumers' surplus

$$
S={ }_{0}^{Z_{Q}} P(Q) d Q \text { i } P(Q) Q
$$

In what follows, we assume that the damage cost function is linear, $D(E)=3 / \mathbb{E}>0$. We de..ne the adjusted marginal damage per unit of output of ..rm i as follows:

$$
\Psi^{\prime} 3 / 4_{i}^{\prime}=
$$

Here, the adjustment factor is $1 \stackrel{\rho}{ } \cdot 1$. The dixerence between $i_{i}$, the optimal tax per unit of ..rm i"s output, and $\ddagger$, its adjusted marginal damage per unit of output, will be called the optimal distortion for ..rm i. We will show that (i) if ..rms are identical, the optimal distortions are equal for all ..rms, and (ii) if ..rms are heterogenous, the optimal 
distortions are no longer equal: higher cost ..rms will be penalized more, relative to lower cost ..rms.

The social welfare at a Cournot equilibrium may be written as

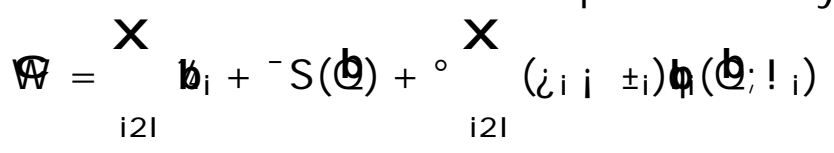

where $\phi=Q(!)$ and $b_{4}$ is given by (9). Note that the ..rst term on the right-hand side of (13) contains tax payments by ..rm (in the expression $\left.b_{f}\right)$ and the third term contains social value of tax revenue ${ }^{\circ} \dot{i}_{i} \mathbf{q}$. These two tax terms do not cancel each other out when ${ }^{\circ} \in 1$. From expression (13), we see that welfare can be maximized by an appropriate choice of the ..rm-specic tax rates $i_{i}$. However, as we demonstrate below, it is analytically much more convenient to solve the welfare maximization problem by using the equilibrium outputs $\mathbf{q}$ as choice variables, and afterward infer the optimal taxes. The two methods yield the same solution. We now transform variables so that the $i_{i}$ 's are no longer explicitly present in the objective function. We will below how to replace the $\iota_{i}$ 's in (13) by equilibrium quantities. From the equilibrium condition (4),

$$
p q \mathbf{q}+\mathbf{p}=d_{i}+i_{i}+c q(\mathbf{q})
$$

we get

$$
\text { Li i } \left.\quad+=\mathbf{q}^{0}+\left(\boldsymbol{P}_{\mathrm{i}} \mathrm{d}_{\mathrm{i}} \mathrm{i} \quad+\right) \text { i } \quad \mathrm{c}^{9} \mathbf{q}\right)
$$

Substituting (14) into (13), we get

$$
\mathbb{A}=\mathrm{F}\left(\text { (Q) } \mathrm{i}_{\mathrm{i} 21}{ }_{\mathrm{f}_{\mathrm{i}}(\mathbf{q} ; \text {; })}\right.
$$

where

$$
\begin{aligned}
& F(\text { (Q) })^{\prime}-\mathrm{S}\left(\text { (Q) }+{ }^{\circ}\right. \text { 由中 }
\end{aligned}
$$

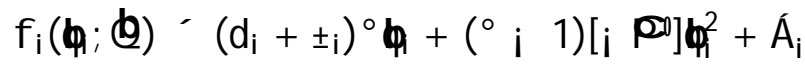




$$
\dot{A}_{i}^{\prime}\left({ }^{\circ} \mathbf{i} 1\right) \mathbf{q} c_{i}{ }^{\prime}(\mathbf{q})+c_{i}(\mathbf{q})
$$

Note that for given $Q, f_{i}$ is strictly convex in $\mathbf{q}$ if ${ }^{\circ}>1, c_{i}^{\infty}, 0$ and $C_{1}^{\infty}$, 0: Expression (15) shows that welfare is directly dependent on the $\mathbf{Q}$ 's. The tax rates do not (explicitly) appear in this expression. Thus $\mathbb{N}$ can be maximized by the direct choice of the equilibium outputs. Afterwards, the taxes can be inferred from (14).

We have thus obtained a very useful lemma:

Lemma 1: In the welfare maximization problem, there is a oneto-one correspondence between determining ..rm-speci..c emission tax rates to maximize welfare, expression (13), and determining Cournot equilibrium outputs to maximize welfare, expression (15).

We note that taxing ..rms is a way of manipulating their marginal costs. Thus, our Pigouvian taxation problem lies within the framwork of the "cost manipulation approach" that we have explained in our previous work (Long and Soubeyran, 1997a, 1997b, 2001a).

\subsection{A benchmark case: perfect competition}

B efore solving for optimal emission taxes in an asymmetric oligopoly, it is useful to consider a benchmark case, with perfect competition. We assume in this subsection that the marginal cost of public fund is unity, $^{\circ}=1$, and the weight given to consumers' surplus is also unity, $-=1$. In this case, we obtain the well-known formula for optimal tax $i_{i}= \pm$, i.e., $t_{i}=3 / 4$ for all $i 2 \mathrm{I}$. (see A ppendix A 1 for details.)

Thus, under perfect competition, all ..rms are treated equally. (We will later show that this "equal treatment" result does not apply to the oligopoly case.) Even though this result is well known, it is useful for future reference to state it as a proposition:

Proposition 1: (Benchmark Pigouvian Tax: fair treatment) Under perfect competition, the optimal Pigouvian tax $t_{i}$ (per unit of emission) is the same for all ..rms and equal to the marginal damage $3 / 4$

$$
t_{i}=3 / 4 \text { for all i } 2 \mathrm{l} \text { : }
$$


Thus all ...rms are treated fairly.

Recall that by de..nition, $\dot{ }_{i}={ }{ }_{i} t_{i}$. Thus, proposition B1 implies that, under perfect competition, the optimal tax per unit of output is $\dot{L}_{i}^{B}=3 / 4_{i}$ where the superscript B indicates the optimal value for the benchmark case.

\subsection{An oligopoly with constant marginal cost}

Now we turn to the case of an oligopoly with constant marginal cost: $c_{i}(q)=\mathbb{Q}_{q} q$. (The increasing marginal cost case is treated in section 4.) In this case, (17) becomes

$$
\mathrm{f}_{\mathrm{i}}(\mathbf{q} ; \text { Q) })^{\prime}\left(\mathrm{d}_{\mathrm{i}}+\mathbf{t}_{+}+\mathbb{B}\right)^{\circ} \mathbf{q}+\left({ }^{\circ} \mathrm{i} 1\right)[\mathrm{i} \mathbf{P}] \mathbf{q}^{2}
$$

We de.ne the marginal social cost of ..rm i's output as

$$
\mathrm{S}^{\prime} \mathrm{d}_{\mathrm{i}}+\mp+\mathbb{Q}
$$

Thus, marginal social cost consists of production cost, ®, transport cost, $\mathrm{d}_{i}$, and adjusted marginal damage, + .

We consider two sub-cases: (a) ${ }^{\circ}=1$ and (b) ${ }^{\circ}>1$.

\subsubsection{Sub-case $(a):^{\circ}=1$}

In this sub-case, the marginal cost of public fund is unity. It is easy to show that the optimal policy is to design taxes so that only the ..rm with the lowest marginal social cost will produce. (See Appendix A 2).

\subsubsection{Sub-case $(b):{ }^{\circ}>1$}

In this sub-case, (17) becomes

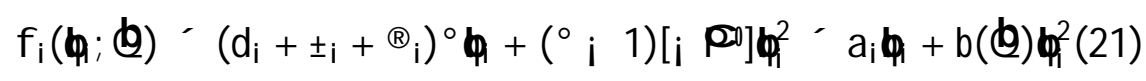


where $a_{i}{ }^{\prime}{ }^{\circ} S_{i}$ is the weighted marginal social cost of ..rm i's output, and

$$
\text { bl(Q) })^{\circ}\left({ }^{\circ} \text { i } 1\right)[i \text { p }]:
$$

For given $\Phi$, the function $f_{i}(\mathbf{q}$; $(\mathbf{Q})$ is quadratic and strictly convex in q. A very exective way to characterize the optimal outputs is to use the following two-step procedure. (See A ppendix A2).

Our result can be summarized as follows:

(i) The optimal industry output is given by $Q$ which is the solution of the following ..rst order condition (please see A ppendix A 2 for details):

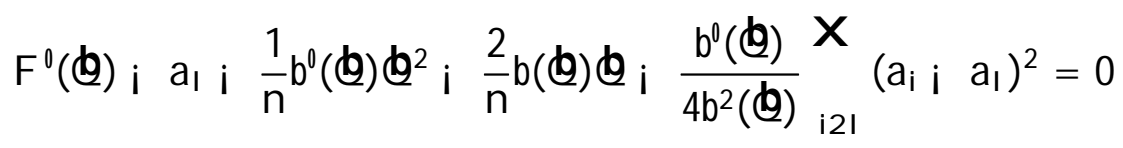

(ii) The optimal output for ..rm $\mathrm{i}$ is

$$
\boldsymbol{\Theta}^{\alpha}=\frac{Q \text { i } a_{i}}{2 b(Q)} \text { for all i } 2 \text { । }
$$

where, $Q$ is given by:

$$
{ }^{3}{ }^{\prime}{ }^{\prime}=a_{1}+\frac{2}{n} b(Q) Q Q
$$

and this implies that the optimal ..rm-speci...c tax rate ..rm $\mathrm{i}$ is given by

$$
\varepsilon=q^{\alpha} P(Q)+\left(P(Q) i d_{i}\right) i
$$

where $\boldsymbol{q}^{\alpha}$ is given by 22

(iii) Let

$$
\phi^{\prime} \text { \& } \mathrm{i} \text { 廿 }
$$


denote the gap between the optimal ..rm-speci..c output tax $i_{i}$ under oligopoly and the adjusted damage cost $¥$. Then$$
\phi_{i}=\Theta^{x} P(Q)+P(Q) i s_{i}=\frac{\left(2 i^{\circ}\right) s_{i}}{2\left({ }^{\circ} i 1\right)}+P(Q) i \frac{, Q}{2\left({ }^{\circ} i 1\right)}
$$

We thus can state:

Proposition 2: (Selective penalization) For any pair of ..rm $(i ; j)$, we have

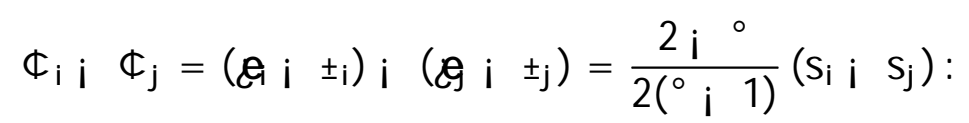

Proof:T his follows from equation 25

To understand the formula (26), consider ..rst the special case where ${ }_{i}={ }_{j}$, so that the marginal damage per unit of output is the same for both ..rms $+=+$ : Then, if $s_{i}<s_{j}$, the optimal selective tax rates are such that $\&<$ \&, provided $1<{ }^{\circ}<2$. That is, the more ed cient ..rm pays a lower tax rate if $1<{ }^{\circ}<2$. However, note that $\left(2 i^{\circ}\right)=2\left({ }^{\circ} i 1\right)$ is a decreasing function of ${ }^{\circ}$; therefore the gap $\varepsilon i$ \& becomes narrower as ${ }^{\circ}$ increases (because with a greater ${ }^{\circ}$, revenue considerations become more important, and therefore the government increases the tax rate on the bigger ..rms). When ${ }^{\circ}=2$, the tax rates are equal ${ }^{6}$.

The intuition behind proposition 1 is as follows. Recall that in an oligopoly with ..rms having dixerent production costs, it is in general not optimal to tax ..rms equally for their pollution. This is because the Pigouvian taxes now serve two purposes: correction for pollution externalities, and correction for market power and for production ineł ciency (because oligopolists do not equalize marginal production costs among themselves) while taking into account the marginal cost of public funds $\left({ }^{\circ}>1\right.$.) We now seek to characterize the optimal departure from the benchmark Pigouvian taxes $\ddagger$ obtained in Proposition1.

\footnotetext{
${ }^{6} \mathrm{For}^{\circ}>2$; the more ed cient ..rm must pay a higher tax rate. Recall that in our speci..cation of the welfare function, we exclude the case ${ }^{\circ}>2$ :
} 
From (67) in the appendix, at the optimal solution, the taxes are such that the more ed cient ..rms (those ..rms with low $\mathrm{s}_{\mathrm{i}}$ ) always produce more than the less ed cient ones. The quantity $\phi_{i}$ measures the deviation of optimal ..rm-speci..c tax under oligopoly from the ..rm-speci..c marginal damage cost caused by a unit of output of ..rm i. Recall that in this section we assume that $2>^{\circ}>1$ (to be in line with the empirical estimation of the marginal cost of public fund by Ballard et al.,1985) and that $c_{i}(z)={ }^{2} z$. We will call $\$ ;$ the optimal Pigouvian distortion for ..rm i.

We now characterize the deviation of $\phi i$ from the industry average \$. From (26),

$$
\phi_{i} \mathrm{i} \phi_{1}=\frac{2 \mathrm{i}^{\circ}}{2\left(^{\circ} \mathrm{i} 1\right)}\left(s_{\mathrm{i}} \mathrm{i} s_{1}\right)
$$

where $s_{i}$ is the marginal social cost of ..rm i's output. This result shows that the ed cient tax structure favors the ed cient ..rms, but this favor falls as ${ }^{\circ}$ increases.

From this, we can compute the variance of the statistical distribution of the Pigouvian distortions:

$$
\operatorname{Var} \phi={\frac{2 \mathrm{i}^{\circ}}{2\left(^{\circ} \mathrm{i} 1\right)}}^{.2} \operatorname{Var}[\mathrm{s}]
$$

Proposition 3: (Optimal distortion theorem)

Optimal Pigouvian distortions (the gaps between optimal tax and adjusted marginal damage) are not equalized in a heterogeneous oligopoly. In the empirically relevant range of the marginal cost of public ..nance $\circ$, i.e., for $1<{ }^{\circ}<2$, if the marginal social cost $s_{i}$ of ..rm $i$ is greater than the industry average, the Pigouvian distortion for ...rm i will be greater than average Pigouvian distortion. The optimal tax structure penalizes ined cient ..rms.

The variance of the distribution of the Pigouvian distortions is given by (28), and it is a decreasing function of ${ }^{\circ}$.

Remark: In the rather extreme case where ${ }^{\circ}>2$ (which is unlikely from empirical data) if the marginal social cost $s_{i}$ of ..rm $i$ is 
greater than the industry average, the Pigouvian distortion for ..rm i will be smaller than average Pigouvian distortion. It remains true that the optimal solution implies that the more el cient ..rms have greater outputs, see (67).

The Optimal Distortion Theorem provides a link between the exante heterogeneity of the oligopoly's cost structure and the ex-post dispersion of the ..rm-speci..c Pigouvian tax rates.

\section{Further Interpretation}

Our results on ..rm-speci..c pollution taxes can be given an interesting geometric interpretation (see the Projection Theorem below) and an industrial organization interpretation (see the Concentration Motive Theorem below).

\subsection{A geometric interpretation: the Projection Theorem}

We now provide a geometric interpretation of the optimal choice of outputs. Consider the ..rst step in the two-step procedure explained in section 2.5.2. That step is equivalent to the program of choosing the $\mathbf{q}$ ( $\mathrm{i}$ 2 l) to

$$
\min ^{X} f_{i}(\mathbf{q} ; \dot{Q})
$$

i21

subject to ${ }_{\text {i2l }}^{\mathbf{P}} \mathbf{q}=\mathbb{Q}$ (given) and $\mathbf{q}$ positive. This step can be described by the following Projection Theorem.

Proposition 4 (Projection Theorem) The determination of the optimal composition of industry output is equivalent to choosing a vector $\mathbf{q}^{\prime}\left(\mathbf{q}_{\mathbf{1}} ; \ldots ; \mathbf{q}_{\mathbf{n}}\right)$ from an $\mathrm{n}$ i 1 dimensional simplex $\mathrm{S}$ so as to minimize the distance between the vector $\mathbf{q}$ and a reference vector $q^{\alpha \prime}\left(q_{n}^{a} ;:: ; ; q_{h}^{\alpha}\right)$ where

$$
q^{x} \cdot i \frac{a_{i}}{2 b(d)}
$$


and where

$$
S^{\prime} \mathrm{fq}, 0::^{X} \quad \mathbf{q}=\phi g
$$

i21

Proof:

$$
\begin{aligned}
& f_{i}\left(\mathbf{q} ; \text { (Q) }=a_{i} \mathbf{q}+b(\text { Q) }) \mathbf{q}^{2}=b(\text { Q) })^{3} \mathbf{q}+{\frac{a_{i}{ }^{\prime}}{2 b}}^{2} i{\frac{a_{i}^{2}}{4 b^{2}}}^{\prime}\right. \\
& =b^{h_{i}} q i q^{\alpha} \phi_{2} i^{\alpha} \phi_{2}^{\phi_{2}^{i}}
\end{aligned}
$$

Thus

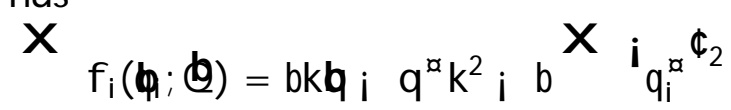

i21

where the second term on the right-hand side depends only on $Q$, which is ..xed, and the ..rst term on the right-hand side is $b$ times the square of the distance of the point $\mathbf{q}$ in the set $\mathbf{S}$ (which is an $\mathrm{n}_{\mathrm{i}}$ simplex) to the given point $\mathrm{q}^{\not}$. Given $Q$, both $b$ and $\mathrm{q}^{\not}$ are ..xed. It follows that the ..rst step (62) of the program is equivalent to ..nding the minimal distance between $\mathbf{q}$ and the given point $\mathbf{q}^{\mathbb{\alpha}}$ :

The optimal $\mathrm{q}$ which achieves the minimal distance $\mathrm{kb}_{\mathrm{i}} \mathrm{q}^{\mathbb{\alpha}} \mathrm{k}$ is the projection of $\mathrm{q}^{\not}$ on the $\mathrm{n}_{\mathbf{i}}$ simplex $\mathrm{S}$. Its components are given by

$$
\mathbf{q}=\mathbf{\theta} i \frac{1}{2 b(\mathbb{Q})}\left(a_{i} ; \quad a_{l}\right)
$$

which is (66). Figure 1 illustrates the case $n=2$. The projection 9 satis.es

$$
\boldsymbol{q}=q^{\alpha}+\left(\boldsymbol{q} ; q^{\alpha}\right) u
$$

where $u=(1 ; 1 ; \ldots: ; 1)$ where $q^{p}=i \frac{a_{1}}{2 b(\Phi)}$. 


\subsection{The Concentration Motive}

Our result shows that ..rm-speci..c Pigouvian taxes in a polluting oligopoly serve two functions: the usual function of correcting for externalities, and the function of correcting for production el ciency, while taking into account the marginal cost of public funds. For this second function, the optimal tax vector depends on two elements (i) the degree of unit-cost asymmetry in the oligopoly, and (ii) the cost of public fund. The ..rst element is measured by the variance of the statistical distribution of unit costs before and after taxation (this variance is related to the Her..ndahl index.) The second element is measured by ${ }^{\circ}$ and refects the trade-o between pro..ts and tax revenue.

Does the optimal Pigouvian tax structure increase or decrease the concentration of the industry? Before answering this question, it is necessary to examine the relationships among the variance of the distribution of the unit costs, the Her...ndahl index of concentration, industry pro..t, and welfare. We now state a number of lemmas concerning these relationships. First, recall that the Her..ndahl index of concentration is

$$
H={ }_{i 21} \frac{q^{-2}}{Q}
$$

Given that there are $\mathrm{n}$..rms, this index attains its maximum value $(H=1)$ when one ..rm produces the whole industry's output and the remaning $n_{i} 1 \ldots$.rms produce zero output, and it attains its mimimum value $(H=1=n)$ when each of the $n$..rms produces $q=Q=n$. Now all ..rms will produce the same amount of output if they have the same tax-inclusive marginal costs.

Lemma 2: For a given output level $Q$; the Cournot equilibrium industry pro..t is an increasing function of the Her..ndahl index of concentration.

Proof: Recall that at a Cournot equilibrium, ..rm i's pro..t is $\Psi_{4}=\left[i P q q^{2}+\mathbf{q} c_{i}(\mathbf{q}) ; c_{i}(\mathbf{q}) W\right.$ ith $c_{i}(q)=\circledast q$, the industry pro..t 
is

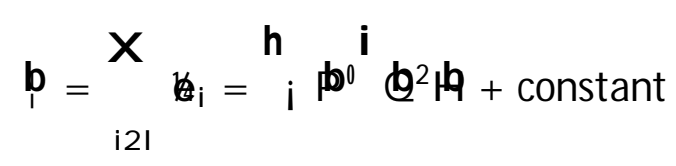

where

$$
\| \phi=x_{i 21}^{x} \frac{q^{-2}}{d}
$$

Lemma 3: Given the output level $\Phi$, the Her..ndahl index of concentration is an increasing function of the variance $\operatorname{Var}\left(B^{9}\right)$ of the distribution of the tax-inclusive marginal costs in a Cournot equilibrium.

$$
\begin{aligned}
& 23
\end{aligned}
$$

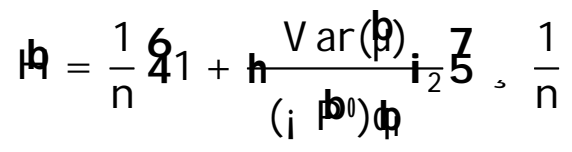

Thus any policy that maximizes [respectively, minimizes] the variance of the distribution of tax-inclusive marginal costs will maximize [respectively, minimizes] the concentration of the industry, and, for a given $Q$, maximizes the pro..t of the industry.

Proof:

From (4),

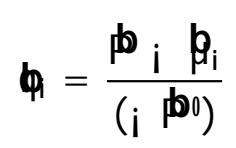

we obtain

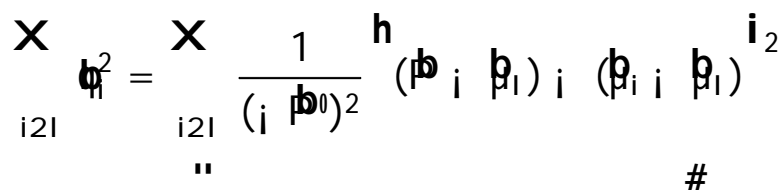

$$
\begin{aligned}
& =\frac{1}{(i \text { ळ })^{2}} n\left(\phi_{i} \phi_{1}\right)^{2}+{ }_{i 21}^{x}\left(\beta_{i} \beta_{i}\right)^{2}
\end{aligned}
$$




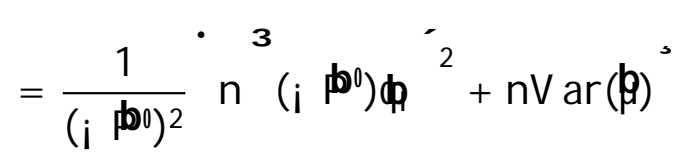

The result (32) follows from (34) and (31).

We now can state an important result: with $^{\circ}>1$, the optimal tax structure increases the concentration of the industry. (See proposition CM below for a precise statement.) This means ineф cient ..rms are penalized more, relative to et cient ..rms. Recall that for the case ${ }^{\circ}=1$, in section 2.5.1, at the social optimum, only the ..rm with the lowest social cost (s) will produce, giving rise to the maximum level of industry concentration (i.e., the Her..ndahl index will take on its highest possible value, 1 ). Here, with $2>^{\circ}>1$, tax revenue is an important consideration, and hence there is a tradeoc between productive el ciency and tax revenue. It is still the case that the optimal tax structure increases the Her..ndahl index, by increasing the variance of the distribution of tax-inclusive marginal costs. We call this the Magni..cation exect:T he magni...cation factor, denoted by - $\left({ }^{\circ}\right)$, is de. ned by

$$
-\left({ }^{\circ}\right)^{\prime} \cdot{\frac{\circ}{\left.2{ }^{\circ} \mathrm{i} 1\right)}}^{.2}>1 \text { for } 2>^{\circ}>1
$$

This magi..cation factor is a decreasing function of ${ }^{\circ}$. As $^{\circ}$ approaches the value 2 , the magi..cation factor falls to 1 .

Proposition 5 (A pro-concentration motive theorem)

Assume that all ..rms have the same emission coed cients: ${ }^{2}{ }_{i}=2$ for all i. Given $2>^{\circ}>1$, the optimal ..rm-speci..c Pigouvian tax structure increases the variance of the statistical distribution of taxinclusive marginal costs within the oligopoly relative to the variance of the statistical distribution of pre-tax marginal costs ${ }^{7}$. The relationship between the two variances is given by:

$$
\operatorname{Var}(\boldsymbol{\beta})=-\left({ }^{\circ}\right) \operatorname{Var}\left(\mu^{0}\right)
$$

\footnotetext{
${ }^{7}$ In the empirically unlileky case where ${ }^{\circ}>2$; replace "increases" by "decreases".
} 
where $\mu_{i}^{0}=d_{i}+{ }^{\circledR}$ is the equilibrium marginal cost of ..rm i in a Cournot equilibrium where all the taxes are zero, and where

Proof: First, note that if all the taxes are zero, then

$$
\mu_{i}^{0} \text { i } \mu_{i}^{0}=\left(d_{i} i d_{l}\right) i \quad\left(d_{l}+\circledast\right)
$$

Recall that $\mathbf{q}$ denote the equilibrium Cournot output of ..rm i given an arbitrary vector of ..rm-speci..c taxes, and $\mathbf{q}$ is the equilibrium Cournot output of ..rm i when the taxes are optimized. From (66), and (33), which is true also when the tilda replaces the hat,

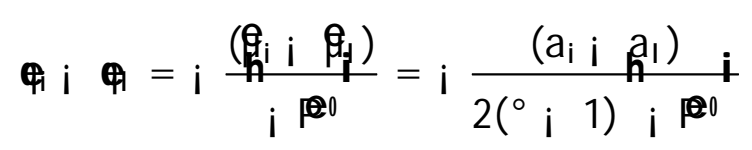

Hence

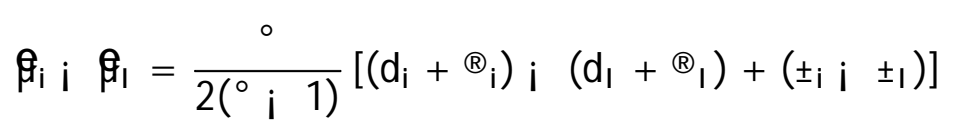

Therefore

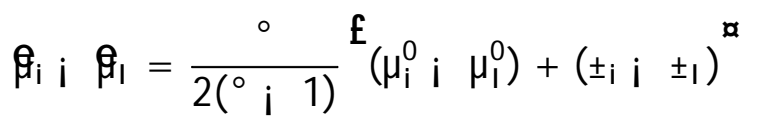

$$
\begin{aligned}
& \operatorname{Var}(\beta)={\frac{\circ}{2\left({ }^{\circ} i 1\right)}}^{.2} f \operatorname{Var}\left(\mu^{0}\right)+\operatorname{Var} \pm+2 \operatorname{cov}\left(\mu^{0} ; \pm^{\alpha}\right.
\end{aligned}
$$

If $z_{i}=2$ for all $i$, then, in view of (1) and (12), (39) reduces to (36). Note that $-\left({ }^{\circ}\right)>1$ if $1<{ }^{\circ}<2$.

R emark: The intuition behind the pro-concentration motive the orem is as follows. If $+= \pm$ for all $i$, the marginal cost of public fund is within the empirically likely range $\left(1<{ }^{\circ}<2\right)$, then, for any given industry output level, the optimal ..rm-speci...c tax structure increases the variance of marginal costs (from $\operatorname{Var}\left(\mu^{0}\right)$ to $-\left({ }^{\circ}\right) \operatorname{Var}\left(\mu^{0}\right)$ ) by taxing more el cient ..rms at a lower rate, see (26), because this helps the lower cost ..rms to expand output relative to the higher cost ..rms, and as a result improves productive et ciency. However, if ${ }^{\circ}$ is great, the 
tax revenue becomes a very important consideration, and it becomes optimal to tax more ec cient ..rms at a higher rate, so as to generate more revenue. Take for example the case of a duopoly, where ..rm 2 has higher production cost. For a given level of industry output $Q$, we must maintain $t_{1}+t_{2}=$ constant, say $2 t$. From an initial assignment $\left(t_{1} ; t_{2}\right)=(t ; t)$, consider deviation of $t_{2}$ from $t$, say $t_{2}=t+\cdot$, and hence $t_{1}=t_{i} \cdot$. An increase in $\cdot$ yields marginal gain in production ed ciency, because the same level of industry output $\phi$ is produced, but the lower cost ..rm increases its output and the higher cost ..rm reduces its output. However, an increase in - by $\phi$ - implies reduced tax revenue, by approximately $\left(\mathbf{b}_{\mathbf{1}} ; \mathbf{b}_{\mathbf{k}}\right) \phi \cdot ;$; plus the exect of induced changes in composition of industry output) and this implies increased distortion cost, approximately $\left({ }^{\circ} \mathrm{i} 1\right) \phi \cdot\left(\mathbf{q}_{\mathbf{1}} \mathbf{i} \mathbf{Q}_{\mathbf{k}}\right)$. For a given ${ }^{\circ}>1$, the optimal deviation ${ }^{\circ}$ is at the point where the marginal gain in productive ec ciency is equated to the marginal increase in distortion cost. Clearly, a higher ${ }^{\circ}$ shifts the marginal distortion cost upwards, implying a smaller $\cdot$.

\section{Selective Penalization under Non-linear Costs}

We now examine the the case where $c_{i}\left(z_{i}\right)$ is strictly convex. To simplify the exposition, we assume that the marginal cost of public fund is unity: ${ }^{\circ}=1$. In this case, the functions $f_{i}(\mathbf{q} ;$ (Q) become

$$
\mathrm{f}_{\mathrm{i}}(\mathbf{q} ; \text { i })=\left(\mathrm{d}_{\mathrm{i}}+\mp_{+}\right) \mathbf{q}+\mathrm{c}_{\mathrm{i}}(\mathbf{q})=\mathrm{g}(\mathbf{q})
$$

The ..rst stage of the game can be solved in two steps: In step (i), we solve

$$
\max _{\mathbf{q}} \mathbb{W}=F^{3} \mathbb{Q}^{\prime} i_{i 21}^{X} f_{i}(\mathbf{q} ; \dot{Q})
$$

where

$$
\mathrm{F}^{3} \mathrm{Q}^{\prime},-\mathrm{S}(\mathrm{Q})+\mathrm{QP}(\mathrm{Q})
$$


subject to

$$
{ }_{i 21}^{x} \mathbf{q}=\text { Q }
$$

where $\mathbb{Q}$ is given, and $q, 0$. In step (ii), we determine the optimal Q.

To solve step (i), we form the Lagrangian

$$
\underline{b}=\mathrm{F}^{3} \boldsymbol{Q}^{\prime} \mathrm{i}_{\mathrm{i} 21}^{\mathrm{x}} \mathrm{f}_{\mathrm{i}}(\mathbf{q} ; \dot{\phi})+{ }_{\mathrm{i} 21}^{\mathrm{x}} \mathbf{q}_{\mathrm{i}} \boldsymbol{\phi}^{\#}
$$

or

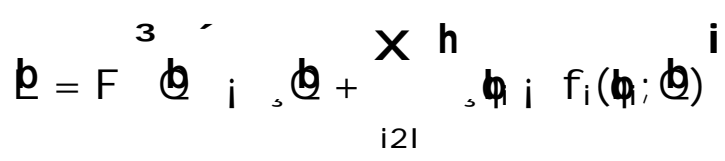

We obtain the ..rst order conditions

$$
\frac{\mathbb{d}_{i}}{\mathbb{c}_{\mathbf{q}}}=d_{i}+++c_{i}^{0}(\mathbf{q})=\text {. }
$$

hence

$$
\mathbf{q}=c_{i}^{x}\left(, \quad i \quad d_{i} i \quad ¥\right)
$$

where $c_{i}^{\times}(:)$is the inverse function of $c_{q}^{Q}(:)$. Then $\mathbf{q}()=,c_{i}^{\times}\left(, i_{i} d_{i}+\right.$ ). The equation i2l $\mathbf{q}()=$, Q determines a unique ( $(\mathbb{Q})$.

The second step: We now determine the optimal $Q$. We follow the duality method used in Rockafellar (1970). Following Rockafellar, we de. ne the conjugate function

$$
f_{i}^{\alpha}(, ; \Phi)=\sup _{\mathbf{q}}{ }^{h}, \mathbf{q} i f_{i}(\mathbf{q} ; \text { (d) }
$$

then

$$
f_{i}^{\alpha}(, ; Q)=, \theta(,) ; f_{i}(\boldsymbol{\theta}(,) ; \text { Q })
$$


It follows that the optimal value of the Lagrangian (optimized with respect to the $\mathbf{q}$ ) is

$$
e(\mathbb{Q})={ }^{h} F(\mathbb{Q}) i,(\mathbb{Q}) \mathbb{Q}^{\mathrm{i}}+{ }_{i 21}^{x} f_{i}^{x}(,(\mathbb{Q}) ; \text { Q })
$$

Dixerentiating $\mathrm{e}(\mathbb{Q})$ with respect to $\mathcal{Q}$ and equating it to zero yields

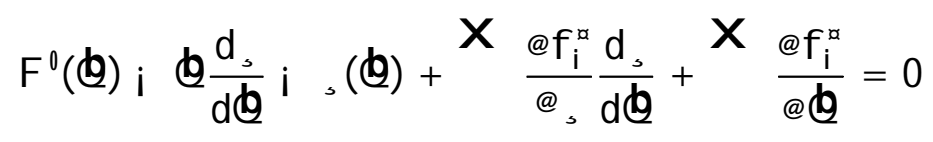

Since

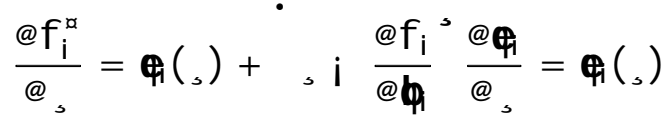

(41) reduces to

$$
F q(Q) \text { i } Q \frac{d}{d \Phi} i,(Q)+{ }_{i 21}^{X} q(,(Q)) \frac{d}{d \Phi}=0
$$

or

$$
\mathrm{F} \text { (Q) } \mathrm{i},(\mathrm{Q})=0
$$

This equation determines the optimal $\mathbb{Q}$.

Now, from (40)

$$
F(\text { Q })=\oplus_{i}\left(1 i^{-}\right)^{h} \text { 由 } 0^{i} \text { Q }
$$

From (42) and (43),

$$
\text { 由 } i,=\left(1 i^{-}\right)^{\mathrm{h}} \text { 由 } \text { 由 }^{\mathrm{i}} \text { \& }
$$

The dixerence between the optimal per unit tax and the marginal damage is given by

$$
i_{i} \text { i } ¥=P^{0} \boldsymbol{\theta} \text { i }\left[\left(d_{i}+\mp\right)+c_{i}^{0}(\mathbf{Q})\right]
$$


But, recall that

$$
\left(d_{i}+\ddagger_{+}\right)+c_{i}^{0}(\mathbf{Q})=\text {, }
$$

Therefore

$$
\mathrm{Li}_{\mathrm{i}} \pm=\mathrm{p}_{\mathrm{i}},{ }^{\mathrm{i}}+\boldsymbol{P}_{\mathbf{q}}
$$

From (44) and (46),

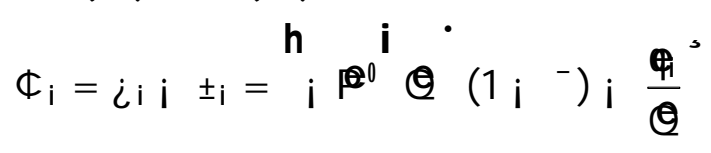

Thus

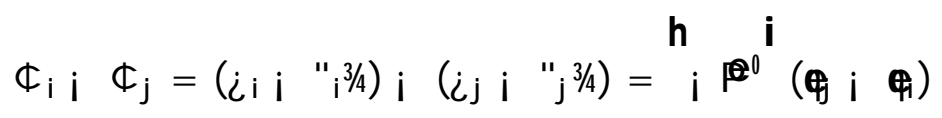

From (47) we can state the following proposition

Proposition 6: (Optimal Pigouvian Distortion under Strictly Convex Costs and ${ }^{\circ}=1$ )

Under strictly convex cost, the optimal tax structure favors lower cost ...rms.

Remark: Under linear cost, if ${ }^{\circ}=1$, the optimal tax structure will eliminate all inec cient ..rms (only the lowest cost ..rm will survive). Under strictly convex cost, such extreme penalization does not emerge; rather, all ..rms will produce, but the more ec cient ..rms are more favorably treated.

Thus the speci..c Pigouvian tax $t_{i}$ on pollution by ..rm $\mathrm{i}$ is

$$
t_{i} \cdot \frac{\Sigma_{i}}{2_{i}}= \pm+\frac{1}{n_{i}} S 9(\Theta) \quad\left(1 i^{-}\right) i \frac{\theta^{\prime}}{Q}
$$

We conclude that (i) $t_{i}$ is greater, the greater is the marginal damage cost, (ii) $t_{i}$ is negatively related to the weight attached to consumers' surplus, and (iii) in equilibrium, among all ..rms that have the same emission coec cient " $i$, smaller ..rms are taxed at a higher rate. This is because smaller ..rms are less eф cient, and optimal policy seeks to reduce their outputs. 
It is easy to generalize the result to the case where ..rm i has $u_{i}$ identical plants. Thus, let $z_{i}=q=l_{i}$ and denote cost at the plant level by $c_{i}\left(z_{i}\right)$. Then optimal policy also favors ..rms with more plants. To see this, consider two ..rms, say ..rm i and ..rm j with $d_{i}=d_{j},+\neq=$ †, and the same cost function at the plant level, i.e., $c_{i}(:)=c_{j}(:)$. Then, equation (45), appropriately modi..ed, gives $\boldsymbol{A}_{\mathbf{A}}$. It follows that $u_{i}>u_{j}$ then $\mathbf{q}>\boldsymbol{q}$, and therefore, from (48), ..rm i will pay less tax per unit of output than ..rm j. Intuitively, this is because, at the ..rm level, ..rm i has a lower marginal cost curve. It is in this sense a more ed cient ..rm, and accordingly it is better treated. (T his happens only under oligopoly; under perfect competition, both ..rms would be taxed at the same rate.)

Corollary: Firms with more plants will be more favorably treated.

\section{Pollution Standards and A batement Costs}

We now turn to a model in which ..rms can reduce emission at any given output level, by incurring abatement costs (which is a function of both the output level and the emission level). We will focus on the use of ..rm-speci...c pollution standards.

We assume that for a given pollution standard e (the maximum level of emission that ..rm $i$ is allowed), the cost of output $q$ is

$$
A_{i}(e ; q)=a_{i}(e) v(q)
$$

with $a_{i}\left(e_{1}\right)>0$ for all e $, 0, a_{i}^{q}(e)<0, a_{i}^{O}(e), 0, v^{q}(q)>0$, $v^{\mathbb{Q}}(q), 0$, and $v(0)=0$. Thus $A_{i}$ is convex in both arguments, and $A_{i}(e ; 0)=0: T$ hen ..rm i's pro..t is

$$
1 / \mathfrak{A}=q P(Q) \text { i } c_{i} q \text { i } A_{i}(q ; e)
$$

We assume that the regulating agency speci..es an amount e (i.e., maximum pollution per period) that ..rm i must not exceed. We take it that the ..nes for violation are suc ciently high to ensure perfect compliance. It follows that if the ..rm wants to produce quantity $q$ 
then it must spend the amount $A_{i}(\bar{e} ; q)$. We call e the "..rm-speci..c emission standard" set by the regulatory agency.

We wish to determine the optimal con..guration of ..rm-speci..c standards that maximizes social welfare, given the constraints that ..rms are oligopolists.

We now show that welfare can be increased by setting non-identical ..rm-speci..c standards.

Given $e_{1}$..rm i's marginal cost of production is $\left.c_{i}+a_{i}\left(e_{1}\right) v^{9} q\right)$ Then, if $\hat{Q}$ is the Cournot equilibrium industry output, ..rm i's equilibrium output satis..es

$$
\hat{q} P(\hat{Q})+P(\hat{Q})=c_{i}+a_{i}(e) v^{q}(\hat{q})^{\prime} \mu_{i}
$$

where $\mu$ is ..rm i's marginal cost at a Cournot equilibrium. We will exploit the following equilibrium relationship between e, and $\hat{q}$; for $a$ given $\hat{Q}$ :

$$
a_{i}(e)=\frac{P q(\hat{Q}) \hat{q}+P(\hat{Q}) i C_{i}}{V(\hat{q})}
$$

That is,

$$
e(\hat{q} ; \hat{Q})=a_{i}^{i} \frac{\hat{q} \hat{p}^{0}+\hat{p_{i} c_{i}}}{v \underline{q})}
$$

Thus in equibrium, ..rm i's abatement cost is

$$
a_{i}(e) v(\hat{q})=\frac{\left.[P q \hat{Q}) \hat{q}+P(\hat{Q}) ; c_{i}\right] \hat{q}}{\prime(\hat{q})}
$$

where ${ }^{\prime}(q)$ is de. ned as the elasticity of $v(q)$ : ${ }^{\prime}(q)=q v^{q}(q)=v(q)$.

Equilibrium pro..t of ..rm $i$ is, from (50) and (54),

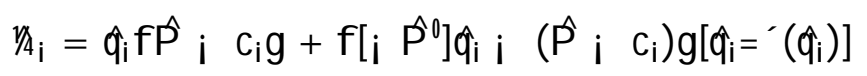

$$
\begin{aligned}
& =\left(\hat{P} \hat{i}_{i}\right) 1_{i} \frac{1}{\prime(\hat{q})}^{\prime} \hat{q}+[i \vec{p}]_{\frac{q^{2}}{(\hat{q})}}
\end{aligned}
$$


Industry pro..t in equilibrium is

$$
\hat{i}={ }_{i}^{X} r y_{A}=\hat{Q}^{2}\left[i \vec{P} \hat{p} \phi+{ }_{i}^{X}\left(\hat{P} i c_{i}\right) 1 i \frac{1}{(\hat{q})}^{\prime} \hat{q}\right.
$$

where $\mapsto$ is a "modi..ed Her..ndahl index" of concentration:

$$
\|=\underbrace{X}_{i 21} \frac{\hat{q}^{2}}{(\hat{q}) \hat{Q}^{2}}
$$

We can express social welfare as

$$
A=-S(\hat{Q}){ }_{i 2 N}^{X} f_{i}(\hat{q} ; \hat{Q})
$$

where

$$
\begin{aligned}
& f(\hat{q} ; \hat{Q})^{\prime} ;\left[P(\hat{Q}) ; c_{i}\right] 1 ; \frac{1}{\prime}(\hat{q})^{\prime} \hat{q} \\
& +\hat{P}^{0} \frac{\hat{q}^{2}}{(\hat{q})}+3 / Q(\hat{q} ; \hat{Q})
\end{aligned}
$$

For any given $\hat{Q}$, the regulator can choose the $\hat{q}$ 's to maximize social welfare subject to ${ }_{i 21} \hat{q}=\hat{Q}$ : An interesting property of the social welfare function (56) is that, under certain reasonable assumptions, it is convex in the $\hat{q}$ 's, for a given $\hat{Q}$ : For example, we obtain this convexity property if $\mathrm{v}(\mathrm{q})=\mathrm{q}, \mathrm{a}(\mathrm{e})=\mathrm{B}$ i e where $\mathrm{B}>0$, and $P(Q)=1 ; Q$. We can now the following proposition.

Proposition 7: When pollution abatement cost is of the form given by (49), optimal standards satisfy the following properties:

(i) If the social welfare function is concave in the $\hat{q}^{\prime} \mathrm{s}$, the optimal ..rm-speci..c pollution standards are

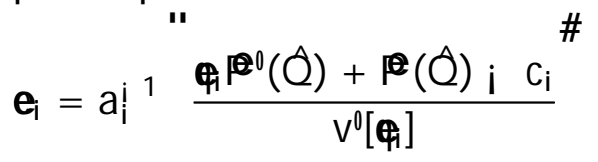


(ii) (U nequal treatment of equals): If the social welfare function (56) is convex in the $\hat{q}^{\prime} s$, the optimum choice of the $\hat{q}^{\prime}$ 's is achieved by giving non-identical treatments to identical ..rms.

R emark: For lack of space, we do not present results on the direction of bias here. Some examples are provided in Long and Soubeyran (2001b). Similar results apply to the case of tradeable permits, see Long and Soubeyran (2000).

\section{Concluding remarks}

We have characterized the optimal structure of penalties for polluting ..rms in an oligopoly with heterogenous costs. We have shown that there is a bias in favor of e\& cient ..rms. In achieving eф ciency, a structure of systematic biases emerges.

Our paper goes beyond the existing result of unequal treatment to ex ante identical ..rms. Several important insights emerge. It is shown that optimal ..rm-speci..c regulations are partly driven by the motive to increase the industry concentration, because increased concentration can enhance productive eфc ciency. However, tax revenue can be an important consideration, and any increase in the marginal cost of public funds would lead to an increased tax rate on the more eq cient ..rms. The degree of industry concentration is increased by the structure of et cient taxes.

Our analysis can be extended to study the role of strategic trade policy in the presence of a polluting international oligopoly. There are a number of insightful papers that deal with this topics (Conrad (1993), Barrett (1994), Kennedy (1994), Ulph and Ulph (1996), Ulph (1996a,b), Neary (1999)). However, the optimal structure of taxes

was not explored in these papers, because the models did not allow for asymmetry within the domestic industry, and ..rm-speci..c taxes or standards were ruled out.

APPENDIX A 1

The benchmark case: perfect competition. 
Perfect competition means that each ..rm thinks that its output has no exect on the price, i.e., the term $P Q Q$ ) does not appear (i.e., is assigned the value zero) in the ..rm's ..rst order condition. Therefore (14) reduces to

$$
i_{i}=\phi_{i} \quad d_{i} \text { i } c(\mathbf{q})
$$

With ${ }^{\circ}={ }^{-}=1$ social welfare (15) becomes

$$
\mathbb{W}=\mathrm{S}(\mathbf{Q})+\mathbb{D Q} \mathbb{Q}_{\mathrm{i}}{ }^{X}\left[\left(d_{i}+\Psi_{i}\right) \mathbf{q}+c_{i}(\mathbf{q})\right]
$$

Writing $Q={ }^{P}{ }_{i 21} \mathbf{q}$ and maximizing (59) with respect to the $\mathbf{q}$ 's, we obtain

$$
\text { 由) } d_{i} \text { i }
$$

which says that marginal social cost of ..rm i's output must be equated to price, a standard result. From (60) and (58), we get $i_{i}= \pm$, and hence, using (1) and (12),

$$
t_{i}=\frac{3 / 4}{0}, \pm \text { for all i } 2 \text { l }
$$

( where $^{\circ}=1$ ) that is, the tax per unit of pollutant discharged by ..rm $i$ is equal to the marginal damage cost.

\section{APPENDIX A2}

Oligopoly with constant marginal cost.

Subcase $(a):^{\circ}=1$ :

Without loss of generality, assume $s_{1}<s_{2}<s_{3}<:::<s_{n}$. Then, if $\left(\mathbb{N}=F\left(b_{1}=Q^{Q}\right)\right.$ i $s_{1}=0$ it must be true that, for all $\mathrm{j}>1$, $\left(\mathbb{O}=\mathrm{C}=\mathrm{F}(\mathrm{Q}) ; \mathrm{s}_{\mathrm{j}}=\mathrm{s}_{1} ; \mathrm{s}_{\mathrm{j}}<0\right.$, implying that $\mathbf{q}=0$. It follows that at the social optimum, only ..rm 1 produces.

An intuitive explanation of this result is as follows. Suppose that at an equilibrium both ..rms 1 and 2 produce positive outputs, and they satisfy the Cournot equilibrium conditions

$$
P\left(\text { Q) }+P q\left(\text { Q) } \mathbf{b}_{1}=d_{1}+\AA_{1}+i_{1}\right.\right.
$$


and

$$
P\left(\text { Q) }+P q\left(\text { Q) } \mathbf{b}_{2}=d_{2}+\mathbb{R}_{2}+i_{2}\right.\right.
$$

Then, social welfare can be increased by raising $i_{2} \neq i \mathrm{P} q($ Q) ] by $\phi>0$ and reducing $\left.i_{1} \neq \mathrm{i} P q(Q)\right]$ by $\phi$, so that ..rm 1's output will increase by $\Varangle$ and ..rm 2's output will fall by $₫$, leaving industry output and price unchanged. Social welfare increases because the total cost of producing the given output $Q$ is now lower. Tax revenue will change, but industry pro..t, de..ned as sales revenue, minus production cost, minus tax payment) will change by the same amount, therefore, given that ${ }^{\circ}=1$, the tax revenue change does not matter.

Subcase (b) ${ }^{\circ}>1$

The two-step procedure:

In step 1 , we ..x an arbitrary level of industry output, $Q$; and paximize welfare by choosing the $\mathbf{q}$ 's subject to the constraint that

${ }_{i 21} \mathbf{q}=\mathbf{Q}$. This gives the optimal value of $\mathbf{q}$, conditional on the given $Q$. In the second step, we determine the optimal industry output.

Step 1:

Given $\mathcal{Q}$, we write the Lagrangian as

$$
L=F\left(\text { Q) } i{ }_{i 21}^{X} f_{i}(\mathbf{q} ; \text { Q })+{ }^{x}{ }_{i 21} \mathbf{q}_{i} \mathbb{Q}^{\#}\right.
$$

From this we obtain the conditions

$$
\text { i } a_{i} \text { i } 2 b(\text { Q) }) q+,=0 \text {; for all i } 2 \text { I }
$$

where $\boldsymbol{q}$ denotes the optimal value of $\mathbf{q}$, conditional on the given $\boldsymbol{\phi}$. From (63),

$$
\mathbf{q}=\frac{\mathrm{i} a_{\mathrm{i}}}{2 b(\mathrm{~d})} \text { for all i } 2 \text { । }
$$


Summing (64) over all $i$, we obtain an expression showing that, is uniquely determined by $\mathbb{Q}$

$$
=e_{,}(\Phi)=a_{1}+\frac{2}{n} b(Q) \Phi
$$

where $a_{1}{ }^{\prime}(1=n){ }_{i 21}^{P} a_{i}$. Substituting (65) into (64), and letting $q^{\prime} \quad Q=n$, we get

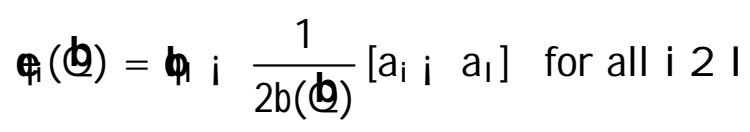

This equation gives us:

Lemma 2: The optimal deviation of the output of ..rm i from average industry output is a linear function of the deviation of its marginal social cost from the industry average.

Remark: To illustrate, consider a pair of ..rms $(1 ; 2)$ with marginal social costs $s_{1}<s_{2}$. Then (66) gives

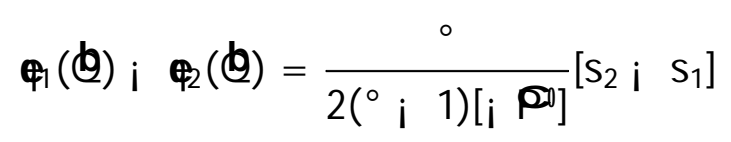

That is, the solution of the optimization problem has the property that the ..rm with higher marginal social cost produces less than the ..rm with lower marginal social cost. Note that, for a given $\phi$, a greater ${ }^{\circ}$ implies a smaller gap between $\boldsymbol{\epsilon}_{1}$ and $\boldsymbol{\epsilon}_{2}$, but this gap is always positive and greater than $\left[s_{2} i \quad s_{1}\right]=2[i \quad q$. This may be explained as follows: a greater ${ }^{\circ}$ implies that a greater weight is given to tax revenue. Thus, for any given $\phi$, a marginal increase in ${ }^{\circ}$ would increase the government's desire to increase tax revenue at the cost of reduced productive ed ciency (here, productive ed ciency includes not only private cost considerations, but also environmental cost). The government would therefore raise $i_{1}$ by some small amount ${ }^{2}>0$ and at the same time reduce $i_{2}$ by ${ }^{2}$, thus leaving total output $\phi$ constant. The increase in tax revenue is approximately $\left(\boldsymbol{\theta}_{\mathbb{1}} \mathbf{i} \mathbf{\theta}_{2}\right)^{2}$ and this must 
be balanced against the marginal loss in productive ed ciency associated with the increase in the output of the high-cost ..rm and the reduced output of the low-cost ..rm.

Step 2:

Using the results in step 1, we are now ready to ..nd the optimal industry output. We make use of the fact that the optimal value of the Lagrangian, given $\Phi$, is equal to the maximized $W$, given $Q$. Thus

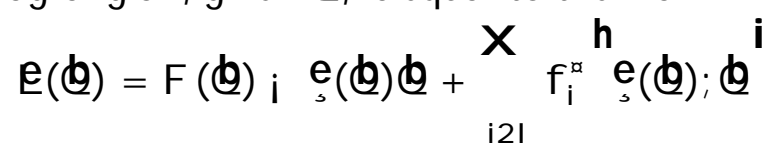

where

$$
f_{i}^{x}(, ; \text {; }) ' \sup _{q}, \mathbf{q} \text { i } f_{i}(\mathbf{q} ; \text { (Q) }
$$

$\left(f_{i}{ }^{\alpha}(, ;\right.$; $)$ is called the conjugate function of $f_{i}(\mathbf{q} ;$ : $)$, see Rockafellar, 1970, section 12.) In the present case,

$$
\begin{aligned}
& f_{i}^{a}(, ; \Phi)=\left[a_{1}+2 b \boldsymbol{q}\right] \mathbf{q} i^{\stackrel{f}{a_{i}} \mathbf{q}+b q^{2}} \\
& ={ }_{i}\left(a_{i} ; \quad a_{1}\right) \mathbf{q} i \quad b\left[\begin{array}{ll}
\mathbf{q} & \mathbf{q}
\end{array}\right]^{2}+b \mathbf{q}^{2}
\end{aligned}
$$

Thus, using (66)

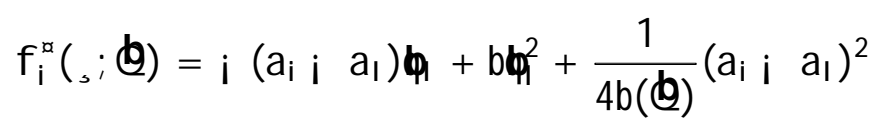

and, using (65), the maximized welfare, for given $\phi$, is

$$
\begin{aligned}
& f\left(\text { Q) }=F\left(\text { Q) } i \quad a_{1}+2 b(\text { () }) \frac{Q^{\#}}{n}\right. \text { Q }\right. \\
& +n b\left(\text { Q) }{\frac{Q^{\prime}}{n}}^{\tilde{n}}+\frac{1}{4 b(\text { Q) }}_{i 21}^{X}\left(a_{i} i \quad a_{1}\right)^{2}\right.
\end{aligned}
$$


Hence

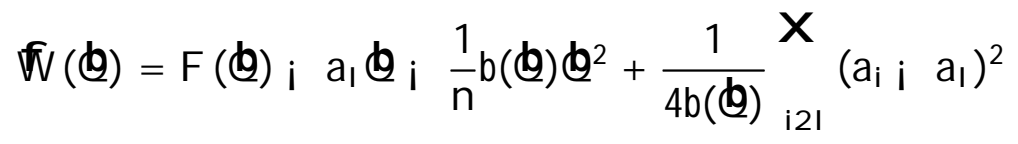

Maximizing (68) with respect to $\mathcal{Q}$, we get the necessary condition

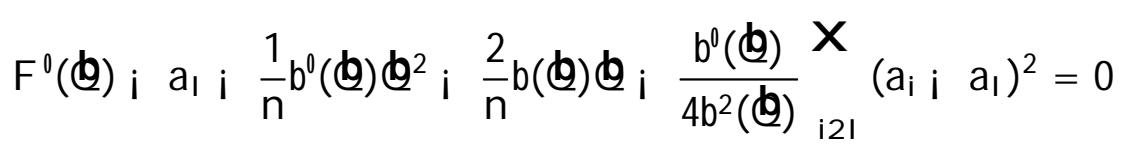

This equation determines the optimal value of $\Phi$, which we denote by Q. The optimal output for ..rm $\mathrm{i}$ is

$$
\mathbf{q}^{\alpha}=\frac{Q i a_{i}}{2 b(Q)} \text { for all i } 2 \text { l }
$$

From this, we derive the optimal ..rm-speci..c tax \&, using (14):

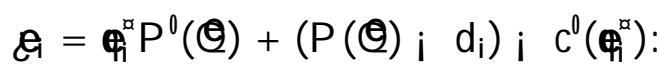

where $\boldsymbol{q}^{\alpha}$ is given by 69

\section{APPENDIX A3}

The Duality A pproach

The following is the outline of the duality approach contained in Rockafellar (1970). Consider the problem

$$
\max _{x_{i}} J=F(X) i_{i 21}^{X} f_{i}\left(x_{i} ; X\right)
$$

subject to

$$
{ }^{X} x_{i}=X, \quad x_{i}, 0 \text {; } i 2 \text { I }
$$

where $X$ is given, $f_{i}\left(x_{i} ; X\right)$ convex with respect to $x_{i}$ and dixerentiable with respect to $\left(x_{i} ; X\right)$, and proper $\left(f_{i}\left(x_{i} ; X\right)\right.$ is never $i 1$, and is not identically +1 ). 
To solve this problem, de. ne the extended functions $g\left(x_{i} ; X\right)=$ $f_{i}\left(x_{i} ; X\right)$ if $x_{i}, 0$ and $g_{i}\left(x_{i} ; X\right)=+1$ if $x_{i}<0$. Then we have the program

$$
\max _{x_{i}} J=F(X) i_{i 21}^{X} g i\left(x_{i} ; X\right)
$$

subject to

$$
{ }_{i 21}^{x} x_{i}=x, \quad \text { i } 2 \text { l }
$$

For agiven $\mathrm{X}$; the Lagrangian of this problem is

$$
L(X ;, ; X)=[F(X) i, X]+{ }_{i 21}^{X}\left[, X_{i} \text { i } g\left(x_{i} ; X\right)\right]
$$

where $x=\left(x_{1} ; \ldots ; x_{n}\right)$.

The saddlepoint duality theorem (see R ockafellar, 1970, pp 284-5) states that $=\left(\mathbb{1}_{1} ;: ; ; \mathbf{B}_{\mathrm{n}}\right)$ is an optimal solution of the program if and only if (i) given, , maximixes the function $L(x ; e ; X)$, and (ii) minimizes $L(A, ; X) ;$, $X)$ with respect to , where $(, ; X)$ achieves the minimum of $L(X ;, ; X)$ for each given, .

The determination of $(, ; X)$ is given by the ..rst order condition of the program

$$
\sup _{x_{i}}\left[, x_{i} \text { i } g_{i}\left(x_{i} ; X\right)\right]=g_{i}^{\alpha}(, ; X)
$$

$g_{i}^{a}(, ; X)$ is called the conjugate function of $g\left(x_{i} ; X\right)$. We have

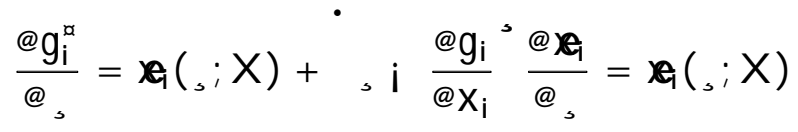

We also have

$$
E=L[(x) ; X) ; ; x]=[F(X) ;, X]+{ }_{i 21}^{X} g_{1}^{\alpha}(, ; X)
$$


and $\mathrm{e}_{,}(\mathrm{X})=\mathrm{e}$, achieves the minimum of $\mathrm{E}$ with respect to, The ..rst order condition for that is

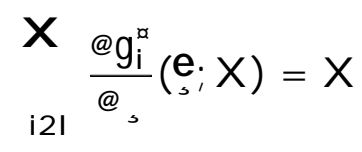

that is,

$$
x \quad(, ; X)=X
$$

i2l

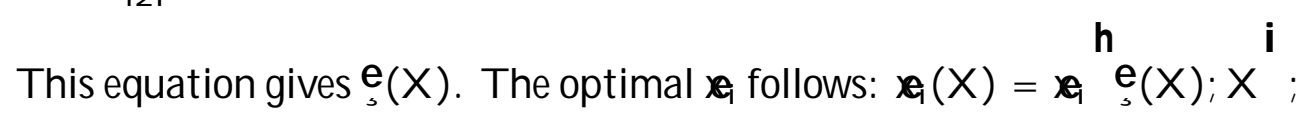
i 2 I:

\section{R eferences}

Ballard, C. L., J. B. Shoven and J. Whalley (1985), General equilibrium computation of marginal welfare costs of taxes in the United States, American E conomic Review 75: 128-38.

B rander, J . A . (1995) Strategic trade policy, Chapter 27, in G. Grossman and K. Rogox, eds., Handbook of International Economics, Volume 3, Elsevier Science Publisher, New York.

B aumol, W. J , and W. E. Oates, (1988), The Theory of Environmental Policy, Cambridge Uinversity Press, Cambridge.

Barnett, A ., (1980), The Pigouvian Tax Rule under M onopoly, American Economic Review 70, 1037-1041.

Barrett, Scott, (1994), Strategic Environmental Policy and International Trade, J ournal of Public Economics, 54(3), 325-38.

B enchekroun, Hassan, and N go Van Long, (1998), E $₫$ ciency-inducing Taxation for Polluting Oligopolists, J ournal of Public Economics 70, 325-342.. 
Buchanan, James M., (1969), External Diseconomies, Corrective Taxes, and Market Structure, American Economic Review 59(1), 174-7.

Conrad, Klaus, (1993), Taxes and Subsidies for Pollution-intensive Industries as Trade Policy, J ournal of Environmental Economics and Management 25, 121-35.

Gaudet, Gérard, and Stephen Salant, (1991), Uniqueness of Cournot Equilibrium: New Results from Old M ethods, Review of Economic Studies 58, 399-404.

Katsoulacos, Y., and A. Xepapadeas, (1995), Environmental Policy Under Oligopoly with Endogenous M arket Structure, Scandinavian J ournal of Economics 97, 411-22.

Kennedy, Peter W., (1994), Equilibrium pollution taxes in open economy with imperfect competition, J ournal of Environmental Economics and Management 27, 49-63.

Long, Ngo Van, and Antoine Soubeyran, (1997a), Cost Manipulation in Oligopoly: a Duality Approach, S.E.E.D.S Discussion Paper 174, Southern European Economics Discussion Series.

Long, Ngo Van, and A ntoine Soubeyran, (1997b), Cost Manipulation in an Asymmetric Oligopoly: the Taxation Problem, S.E.E.D.S Discussion Paper 173, Southern European Economics Discussion Series

Long, Ngo Van, and Antoine Soubeyran, (1999a) Pollution, Pigouvian Taxes, and International Oligopoly, in Emmanuel Petrakis, Eftichios Sartzetakis, and A nastasios X epapadeas (eds.), Environmental Regulation and Market Structure, Edward Elgar.

Long, Ngo Van, and Antoine Soubeyran, (2000a), Existence and Uniqueness of Cournot equilibrium: A Contraction Mapping Approach, E conomics Letters. 
Long, Ngo Van, and Antoine Soubeyran, (2000b), Permis de pollution et Oligopole asymmetrique, É conomie et Prévision, No.133-144, pp. 83-90.

Long, Ngo Van, and Antoine Soubeyran, (2001a), Cost Manipulation Games in Oligopoly, with Costs of Manipulating, International Economic Review, forthcoming.

Long, Ngo Van, and Antoine Soubeyran, (2001b), E mission Taxes and Standards for an A symmetric Oligopoly, CIRA NO working paper, www.cirano.qc.ca/ en/includes/

Luenberger. D., (1969), Optimization by Vector Space M ethods, W iley, New York.

Neary, J. Peter, (1999), International Trade and the Environment: Theoretical and Policy Linkages, Typescript, University College Dublin.

Rauscher, Michael, (1994), Environmental Regulation and the Location of Polluting Industries, Discussion Paper 639, Institute of World Economics, Kiel.

Rauscher, Michael, (1997), International Trade, Factor Movements, and the Environment, Oxford and New York: Oxford University Press, Clarendon Press,

Rockafellar, R. Tyrell, (1970), Convex Analysis, Princeton University Press, Princeton, N.J.

Salant, Stephen and Greg Shafer, (1996, 1999), Unequal treatment of identical agents in Cournot equilibrium, The American Economic Review, vol.89, No. 3, pp.585-604.(An earlier version was available in 1996.) 
Ulph, Alistair, (1992), The Choice of Environmental Policy Instruments and Strategic International Trade, in R.Pethig (ed.) Conficts and Cooperation in Managing Environmental Resources, Springer Verlag, Berlin.

Ulph, A listair, (1996a), Environmental Policy and International Trade When Governments and Producers Act Strategically, J ournal of Environmental Economics and Management 30(3) 265-81.

Ulph, Alistair, (1996b), Environmental Policy Instruments and Imperfectly Competitive International Trade, Environmental and Resource E conomics 7(4) 333-55.

Ulph, Alistair, and David Ulph, (1996), Trade, Strategic Innovation, and Strategic Environmental Policy: A General Analysis, in C. Carraro, Y . K atsoulacos and A. X epapadeas (eds.), Environmental Policy and Market Structure, Dordrecht: K luwer A cademic, 181208. 


\section{Liste des publications au CIRANO*}

Série Scientifique / Scientific Series (ISSN 1198-8177)

2002s-40 Selective Penalization Of Polluters: An Inf-Convolution Approach / Ngo Van Long et Antoine Soubeyran

2002s-39 On the Mediational Role of Feelings of Self-Determination in the Workplace: Further Evidence and Generalization / Marc R. Blais et Nathalie M. Brière

2002s-38 The Interaction Between Global Task Motivation and the Motivational Function of Events on Self-Regulation: Is Sauce for the Goose, Sauce for the Gander? / Marc R. Blais et Ursula Hess

2002s-37 Static Versus Dynamic Structural Models of Depression: The Case of the CES-D / Andrea S. Riddle, Marc R. Blais et Ursula Hess

2002s-36 A Multi-Group Investigation of the CES-D's Measurement Structure Across Adolescents, Young Adults and Middle-Aged Adults / Andrea S. Riddle, Marc R. Blais et Ursula Hess

2002s-35 Comparative Advantage, Learning, and Sectoral Wage Determination / Robert Gibbons, Lawrence F. Katz, Thomas Lemieux et Daniel Parent

2002s-34 European Economic Integration and the Labour Compact, 1850-1913 / Michael Huberman et Wayne Lewchuk

2002s-33 Which Volatility Model for Option Valuation? / Peter Christoffersen et Kris Jacobs

2002s-32 Production Technology, Information Technology, and Vertical Integration under Asymmetric Information / Gamal Atallah

2002s-31 Dynamique Motivationnelle de l'Épuisement et du Bien-être chez des Enseignants Africains / Manon Levesque, Marc R. Blais, Ursula Hess

2002s-30 Motivation, Comportements Organisationnels Discrétionnaires et Bien-être en Milieu Africain : Quand le Devoir Oblige / Manon Levesque, Marc R. Blais et Ursula Hess

2002s-29 Tax Incentives and Fertility in Canada: Permanent vs. Transitory Effects / Daniel Parent et Ling Wang

2002s-28 The Causal Effect of High School Employment on Educational Attainment in Canada / Daniel Parent

2002s-27 Employer-Supported Training in Canada and Its Impact on Mobility and Wages / Daniel Parent

2002s-26 Restructuring and Economic Performance: The Experience of the Tunisian Economy / Sofiane Ghali and Pierre Mohnen

2002s-25 What Type of Enterprise Forges Close Links With Universities and Government Labs? Evidence From CIS 2 / Pierre Mohnen et Cathy Hoareau

2002s-24 Environmental Performance of Canadian Pulp and Paper Plants : Why Some Do Well and Others Do Not? / Julie Doonan, Paul Lanoie et Benoit Laplante

\footnotetext{
* Consultez la liste complète des publications du CIRANO et les publications elles-mêmes sur notre site Internet :
} 
2002s-23 A Rule-driven Approach for Defining the Behavior of Negotiating Software Agents / Morad Benyoucef, Hakim Alj, Kim Levy et Rudolf K. Keller

2002s-22 Occupational Gender Segregation and Women's Wages in Canada: An Historical Perspective / Nicole M. Fortin et Michael Huberman

2002s-21 Information Content of Volatility Forecasts at Medium-term Horizons / John W. Galbraith et Turgut Kisinbay

2002s-20 Earnings Dispersion, Risk Aversion and Education / Christian Belzil et Jörgen Hansen

2002s-19 Unobserved Ability and the Return to Schooling / Christian Belzil et Jörgen Hansen

2002s-18 Auditing Policies and Information Systems in Principal-Agent Analysis / MarieCécile Fagart et Bernard Sinclair-Desgagné

2002s-17 The Choice of Instruments for Environmental Policy: Liability or Regulation? / Marcel Boyer, Donatella Porrini

2002s-16 Asymmetric Information and Product Differentiation / Marcel Boyer, Philippe Mahenc et Michel Moreaux

2002s-15 Entry Preventing Locations Under Incomplete Information / Marcel Boyer, Philippe Mahenc et Michel Moreaux

2002s-14 On the Relationship Between Financial Status and Investment in Technological Flexibility / Marcel Boyer, Armel Jacques et Michel Moreaux

2002s-13 Modeling the Choice Between Regulation and Liability in Terms of Social Welfare / Marcel Boyer et Donatella Porrini

2002s-12 Observation, Flexibilité et Structures Technologiques des Industries / Marcel Boyer, Armel Jacques et Michel Moreaux

2002s-11 Idiosyncratic Consumption Risk and the Cross-Section of Asset Returns / Kris Jacobs et Kevin Q. Wang

2002s-10 The Demand for the Arts / Louis Lévy-Garboua et Claude Montmarquette

2002s-09 Relative Wealth, Status Seeking, and Catching Up / Ngo Van Long, Koji Shimomura

2002s-08 The Rate of Risk Aversion May Be Lower Than You Think / Kris Jacobs

2002s-07 A Structural Analysis of the Correlated Random Coefficient Wage Regression Model / Christian Belzil et Jörgen Hansen

2002s-06 Information Asymmetry, Insurance, and the Decision to Hospitalize / Åke Blomqvist et Pierre Thomas Léger

2002s-05 Coping with Stressful Decisions: Individual Differences, Appraisals and Choice / Ann-Renée Blais

2002s-04 A New Proof Of The Maximum Principle / Ngo Van Long et Koji Shimomura

2002s-03 Macro Surprises And Short-Term Behaviour In Bond Futures / Eugene Durenard et David Veredas

2002s-02 Financial Asset Returns, Market Timing, and Volatility Dynamics / Peter F. Christoffersen et Francis X. Diebold

2002s-01 An Empirical Analysis of Water Supply Contracts / Serge Garcia et Alban Thomas

2001s-71 A Theoretical Comparison Between Integrated and Realized Volatilities Modeling / Nour Meddahi 
2001s-70 An Eigenfunction Approach for Volatility Modeling / Nour Meddahi

2001s-69 Dynamic Prevention in Short Term Insurance Contracts / M. Martin Boyer et Karine Gobert

2001s-68 Serial Cost Sharing in Multidimensional Contexts / Cyril Téjédo et Michel Truchon

2001s-67 Learning from Strike / Fabienne Tournadre et Marie-Claire Villeval

2001s-66 Incentives in Common Agency / Bernard Sinclair-Desgagné

2001s-65 Detecting Mutiple Breaks in Financial Market Volatility Dynamics / Elena Andreou et Eric Ghysels

2001s-64 Real Options, Preemption, and the Dynamics of Industry Investments / Marcel Boyer, Pierre Lasserre, Thomas Mariotti et Michel Moreaux

2001s-63 Dropout, School Performance and Working while in School: An Econometric Model with Heterogeneous Groups / Marcel Dagenais, Claude Montmarquette et Nathalie Viennot-Briot

2001s-62 Derivatives Do Affect Mutual Funds Returns : How and When? / Charles Cao, Eric Ghysels et Frank Hatheway

2001s-61 Conditional Quantiles of Volatility in Equity Index and Foreign Exchange Data / John W. Galbraith, Serguei Zernov and Victoria Zinde-Walsh

2001s-60 The Public-Private Sector Risk-Sharing in the French Insurance "Cat. Nat. System" / Nathalie de Marcellis-Warin et Erwann Michel-Kerjan

2001s-59 Compensation and Auditing with Correlated Information / M. Martin Boyer et Patrick González

2001s-58 Resistance is Futile: An Essay in Crime and Commitment / M. Martin Boyer

2001s-57 The Unreliability of Output Gap Estimates in Real Time / Athanasios Orphanides et Simon van Norden

2001s-56 Exact Nonparametric Two-Sample Homogeneity Tests for Possibly Discrete Distributions / Jean-Marie Dufour et Abdeljelil Farhat

2001s-55 Les coûts de la réglementation : une revue de la littérature / Robert Gagné, Paul Lanoie, Pierre-Carl Micheud et Michel Patry

2001s-54 Testing for structural Change in the Presence of Auxiliary Models / Eric Ghysels et Alain Guay

2001s-53 Environmental Regulation and Productivity: New Findings on the Porter Hypothesis / Paul Lanoie, Michel Patry et Richard Lajeunesse

2001s-52 The Aftermarket Performance of Initial Public Offerings in Canada / Maher Kooli et Jean-Marc Suret

2001s-51 Capital Structure and Risk Management / Karine Gobert

2001s-50 The Underpricing of Initial Public Offerings: Futher Canadian Evidence / Maher Kooli et Jean-Marc Suret

2001s-49 How Innovative Are Canadian Firms Compared to Some European Firms? A Comparative Look at Innovation Surveys / Pierre Mohnen et Pierre Therrien

2001s-48 A Tale of Two Ports / Ngo Van Long et Kar-yiu Wong

2001s-47 Wage Policy of Firms: An Empirical Investigation / Stéphanie Lluis 